\title{
VALUASI EKONOMI MANFAAT LANGSUNG DAN TIDAK LANGSUNG KAWASAN WADUK MALAHAYU, KABUPATEN BREBES
}

\author{
The Economic Valuation Of Benefits Direct and Indirect Malahayu Reservoirs, Brebes
}

\author{
Sofiana, Anhar Solichin*), Dian Wijayanto
}

Program Studi Manajemen Sumberdaya Perairan, Departemen Sumberdaya Akuatik Fakultas Perikanan dan Ilmu Kelautan, Universitas Diponegoro

J1. Prof. Soedarto, SH, Tembalang, Semarang, Jawa Tengah - 50275, Telp/Fax. +6224 7474698 Email : sofychusna@gmail.com

\begin{abstract}
ABSTRAK
Waduk Malahayu merupakan waduk yang mempunyai peranan penting baik bagi warga masyarakat sekitar maupun bagi pemerintah Kabupaten Brebes. Hal ini dikarenakan warga masyrakat memanfaatkan Waduk Malahayu sebagai alat pemenuh kebutuhan mereka seperti kegiatan perikanan tangkap, kegiatan pariwisata, kegiatan penggunaan air bersih, kegiatan transportasi waduk dan kegiatan irigasi sawah. Oleh karena itu Waduk Malahayu menjadi waduk yang perlu dilestarikan keberadaannya untuk menjaga sumberdaya yang mempunyai nilai ekonomi tersebut. Penelitian dilakukan pada bulan Januari-Februari 2016 di Waduk Malahayu yang bertujuan untuk mengetahui secara ekonomi nilai manfaat langsung kawasan Waduk Malahayu dan secara ekonomi manfaat tidak langsung kawasan Waduk Malahayu. Metode yang digunakan yaitu metode penilaian harga pasar untuk sektor perikanan tangkap, metode biaya perjalanan untuk sektor pariwisata, metode Effect on Production Approach(EOP) untuk sektor air bersih dan metode Contingent Valuation Method(CVM) untuk sektor irigasi. Metode penentuan responden menggunakan teknik purposive sampling untuk perikanan tangkap, convenience sampling untuk pariwisata, cluster sampling untuk air bersih, sensus dan convenience sampling untuk transportasi serta purposive sampling untuk irigasi. Hasil penelitian menunjukkan nilai ekonomi manfaat langsung sektor perikanan tangkap yaitu sebesar Rp. 1.369.180.000/tahun, sektor pariwisata yaitu Rp. 3.542.398.400/tahun, sektor air bersih sebesar Rp. 210.360.000/tahun dan sektor transportasi sebesar Rp. 375.407.002/tahun. total nilai ekonomi manfaat langsung yaitu Rp. 5.497.345.402/tahun. Nilai ekonomi manfaat tidak langsung yaitu dari sektor irigasi mempunyai Nilai ekonomi sebesar Rp. 1.101.500.000/tahun.
\end{abstract}

Kata Kunci : Valuasi Ekonomi; Manfaat Langsung; Manfaat Tidak Langsung; Waduk

\begin{abstract}
Malahayu reservoir is a reservoir that has an important role both for the citizens and the government around Brebes. This is because citizens of the community utilizing Malahayu Reservoir as a means of fulfilling their needs as the activities of fisheries, tourism, fresh water, transportation reservoirs and irrigated rice fields plantation. Therefore Reservoir Malahayu into reservoirs that need to be preserved its existence to keep the resources which have economic values. The study was conducted in January-February 2016 in Reservoir Malahayu which aims to determine the economic values of the direct and indirect economic benefits of Malahayu Reservoir area. The method used are the market price valuation method for the fisheries sector, method of travel costs for the tourism sector, the method Effect on Production Approach (EOP) for the water sector and the methods of Contingent Valuation Method (CVM) for the irrigation sector. The method to determine the respondents used purposive sampling techniques for capture fisheries, convenience sampling for tourism, cluster sampling for clean water, census and convenience sampling for transporationt as well as purposive sampling for irrigation. The results showed the economic values of direct benefit fisheries sector is IDR 1,369,180,000 per year, the tourism sector is IDR 3,542,398,400/year, water sector amounting to IDR 210,360,000 per year and the transportation sector amounted to IDR 375,407,002 per year. The total values of the direct economic benefits of IDR 5,497, 345, 402 per year. The economic values of the indirect benefits of the irrigation sector that has economic values of IDR 1,101,500,000per year.
\end{abstract}

Keywords: Economic Valuation, Benefits Direct, Indirect Benefits, Malahayu Reservoirs *) Penulis penanggungjawab

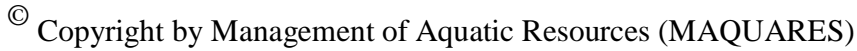




\section{PENDAHULUAN}

Menurut Koeshendrajana et al., (2008), sumber daya waduk termasuk di dalam kelompok sumber daya perairan umum daratan yang merupakan sebuah ekosistem buatan. Berbeda halnya dengan sumber daya perairan umum daratan lainnya (seperti sungai, rawa banjiran dan danau) waduk biasanya memiliki karakteristik hak kepemilikan sumber daya yang bukan non-property. Hak kepemilikan sumber daya waduk dapat bersifat kepemilikan oleh negara (state property) ataupun kepemilikan oleh swasta (private property). Hak kepemilikan sumber daya selalu diasosiasikan dengan dukungan klaim berdasarkan peraturan dan hukum. Peraturan dan hukum ini dapat berbentuk legal formal ataupun konsensus sosial di dalam masyarakat. Klaim atas peraturan dan hukum ini selalu bertujuan "melindungi" seperangkat hak-hak yang melekat bagi pemilik sumber daya.

Sumberdaya yang ada pada kawasan waduk memiliki potensi besar dalam berbagai aspek kehidupan masyarakat. Salah satu waduk yang memiliki potensi tersebut adalah Waduk Malahayu yang terletak di Kecamatan Banjarharjo, Kabupaten Brebes, Jawa Tengah. Waduk Malahayu dibangun untuk berbagai tujuan penting, seperti irigasi, pengontrol banjir, sumber mata air, dan tujuan-tujuan lainnya. Mengingat besarnya potensi yang dimiliki oleh Waduk Malahayu sehingga waduk ini perlu dilakukan studi penilaian ekonomi agar pengelolaan waduk menjadi lebih optimal. Waduk Malahayu terletak di Desa Malahayu, Kecamatan Banjarharjo, Kabupaten Brebes, Jawa Tengah; \pm 6 km dari Kecamatan Banjarharjo atau 17 km dari Kecamatan Tanjung. Luas kawasan ini sekitar 944 hektare dan dibangun pada tahun 1930 oleh Kolonial Belanda.

Bentuk pemanfaatan perikanan merupakan kegiatan yang dominan dilakukan masyarakat di kawasan Waduk Malahayu dan menjadi mata pencaharian bagi masyarakat sekitar berupa penangkapan. Ikan yang terdapat di Waduk Malahayu berupa ikan endemik dan ikan non endemik, ikan endemik Waduk Malahayu yaitu ikan Mendo, ikan Paray dan Keting, sedangkan ikan non endemik yang menjadi komoditas penangkapan yaitu ikan Nila, ikan Mas dan ikan Patin. Di Waduk Malahayu, masyarakat sekitar dan nelayan sepakat untuk tidak melakukan budidaya karamba jaring apung (KJA) dikarenakan masyarakat ingin meminimalisir dampak yang berasal dari KJA.

Pemanfaatan waduk lainnya berupa kegiatan wisata tirta, kegiatan wisata meliputi berperahu mengelilingi waduk dan melihat pemandangan alam sekitar waduk. Untuk mengetahui besarnya nilai ekonomi dari kegiatan perikanan dan wisata di kawasan Waduk Malahayu, maka perlu diadakan penelitian yang dapat mengetahui besarnya nilai ekonomi kawasan tersebut. Berdasarkan hal tersebut, manfaat waduk yang sangat besar sering tidak disadari olehmanusia. Valuasi ekonomi waduk masih dikesampingkan. Padahal dilihat dari fungsi ekologis maupun ekonominya hal ini perlu untuk ditinjau kembali dan dilakukan perhitungan ekonominya. Perhitungan valuasi ekonomi yang perlu dilakukan berdasarkan manfaat terbesarnya yaitu dari bidang irigasi pertanian, pariwisata, pemanfaatan air bersih, transportasi dan perikanan tangkap.

\section{Tujuan penelitian}

Tujuan penelitian valuasi ekonomi ekosistem Waduk Malahayu di Desa Malahayu, Kabupaten Brebes adalah sebagai berikut:

a. Mengetahui secara ekonomi nilai manfaat langsung ekosistem Waduk Malahayu;

b. Mengetahui secara ekonomi nilai manfaat tidak langsung dari sumberdaya Waduk Malahayu.

\section{METODE PENELITIAN}

Penelitian dilakukan di Waduk Malahayu, Kabupaten Brebes. Data yang dikumpulkan meliputi data primer dan data sekunder. Penelitian dilakukan dengan melakukan wawancara terhadap masyarakat sekitar waduk, dan masyarakat yang memanfaatkan Waduk Malahayu serta menggunakan kuesioner.

Metode yang digunakan tersaji dalam tabel berikut :

Tabel 1. Metode Penentuan Responden

\begin{tabular}{llll}
\hline No & Aspek Penelitian & $\begin{array}{l}\text { Subyek } \\
\text { Penelitian }\end{array}$ & Metode Penentuan Respoden \\
\hline 1 & Perikanan Tangkap & Nelayan & Purposive Sampling \\
2 & Pariwisata & Pegunjung & Convenience Sampling \\
3 & Air Bersih & Warga pengguna & Cluster Sampling \\
5 & Transportasi & Penyedia dan & - Penyedia jasa : Sensus \\
& & pengguna jasa & - Pengguna jasa : Convenience Sampling \\
6 & Irigasi & Petani pengguna & Purposive Sampling \\
\hline
\end{tabular}

Data primer meliputi hasil wawancara kegiatan perikanan tangkap nelayan waduk, pemakaian air bersih, dan transportasi waduk. Data sekunder meliputi data kependudukan, irigasi, data sosial ekonomi, data geografis demografis dan penggunaan lahan. Metode penilaian ekonomi yang digunakan yaitu perhitungan nilai manfaat langsung, dan nilai manfaat tidak langsung. 
1. Manfaat langsung (Direct Use Value/DUV)

$\mathrm{TML}=\mathrm{ML}_{1}+\mathrm{ML}_{2}+\mathrm{ML}_{3}+\mathrm{ML}_{4}$

Dimana $=$

TML = Total ManfaatLangsung

$\mathrm{ML}_{1}=$ Manfaat Langsung Perikanan Tangkap

$\mathrm{ML}_{2}=$ Manfaat Langsung Pariwisata

$\mathrm{ML}_{3}=$ Manfaat Langsung Air Bersih

$\mathrm{ML}_{4}=$ Manfaat Langsung Transportasi

2. Manfaat Tidak Langsung (Indirect Use Value/IUV)

TMTL $=$ MTL $_{1}$

Dimana $=$

TMTL = Total Manfaat Tidak Langsung

$\mathrm{MTL}_{1}=$ Manfaat Tidak Langsung Irigasi

Tabel 2. Metode Penilaian Valuasi Ekonomi

\begin{tabular}{lll}
\hline No & Sektor Penelitian & \multicolumn{1}{c}{ Metode } \\
\hline 1 & Perikanan tangkap & Market Price Method \\
2 & Pariwisata & Travel Cost Method $(T C M)$ \\
3 & Air Bersih & Effect on Production Approach $($ EOP) \\
4 & Transportasi & Travel Cost Method \\
5 & Irigasi & Contingent Valuation Method (CVM) \\
\hline
\end{tabular}

Metode perhitungan responden:

1. Purposive Sampling

$N=\frac{n}{n d^{2}+1}$

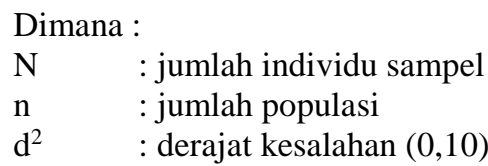

2. Convenience Sampling

Jumlah responden : 30, jumlah ini diasumsikan telah memenuhi sampel dari sektor pariwisata sebagai distribusi normal (Firandari, 2009).

3. Cluster Sampling

Cluster Sampling adalah teknik pengambilan sampel dimana pemilihannya mengacu pada kelompok bukan pada individu, kemudian dikerucutkan kembali menjadi kelompok terkecil. Desa Malahayu terdiri dari 12 dusun, 12 Rukun Warga (RW) dan 33 Rukun Tetangga (RT). Sebagai persyaratan cluster sampling perlu dilakukan edukasi informasi, sehingga hanya diambil 1 RT sebagai kelompok terkecil dari Desa Malahayu.

\section{HASIL DAN PEMBAHASAN}

\section{HASIL}

\section{Keadaan Umum Waduk Malahayu}

Berdasarkan data dari Dinas Kelautan dan Perikanan Kabupaten Brebes tahun 2012, Waduk Malahayu yang berada di Desa Malahayu mempunyai luas $720 \mathrm{Ha}$, dengan kedalaman air $17 \mathrm{~m}$ dan air pasok yaitu dari Sungai Kabuyutan, Sungai Ciomas, Sungai Halimun, dan Sungai Cimandala. Waduk Malahayu secara geografis terletak pada koordinat $108^{\circ} 49^{\prime} 12^{\prime \prime}$ BT dan $07^{\circ} 0$ ' $48^{\prime \prime} \mathrm{LS}$.

\section{Nilai Manfaat Ekonomi Waduk Malahayu}

\section{Manfaat Langsung}

\section{a. Perikanan Tangkap}

Jumlah nelayan di Waduk Malahayu yaitu sebanyak 150 orang. Nilai penerimaan hasil perikanan tangkap tersaji dalam tabel berikut: 
Tabel 3. Estimasi Nilai Hasil Penerimaan Perikanan Tangkap Waduk Malahayu

\begin{tabular}{lcrr}
\hline Jenis Tangkapan & $\begin{array}{c}\text { Jumlah Tangkapan } \\
(\mathbf{K g} / \mathbf{T h}) *\end{array}$ & $\begin{array}{c}\text { Harga Rata-rata } \\
\text { Pasar }(\mathbf{R p / K g})\end{array}$ & Jumlah Nilai (Rp .000/Th) \\
\hline Nila & 214.674 & 10.000 & 2.146 .740 .000 \\
Gabus & 6.203 & 20.000 & 124.060 .000 \\
Patin & 5.463 & 10.000 & 54.630 .000 \\
Mujahir & 244.084 & 10.000 & 2.440 .840 .000 \\
Betutu & 2.096 & 40.000 & 83.840 .000 \\
Mas & 1.095 & 20.000 & 21.900 .000 \\
Udang tawar & 16.598 & 20.000 & 331.960 .000 \\
Ikan lain & 8.769 & 15.000 & 131.535 .000 \\
\hline TOTAL & & & $\mathbf{5 . 3 3 5 . 5 0 5 . 0 0 0}$ \\
\hline
\end{tabular}

Sumber : Hasil Penelitian

Keterangan :

*Jumlah tangkapan berdasarkan data Dinas Kelautan dan Perikanan Kab. Brebes pada tahun 2015.

Tabel 4. Komponen Biaya Perikanan Tangkap Waduk Malahayu

\begin{tabular}{cllr}
\hline No & \multicolumn{1}{c}{ Jenis } & Nilai (/Thn) \\
\hline 1 & Depresiasi Aset & & \\
& - Perahu & Rp. & $587.500,-$ \\
& angkap & Rp. & $3.000 .000,-$ \\
& - Mesin & Rp. & $457.000,-$ \\
2 & Perawatan & Rp. & $331.000,-$ \\
3 & Bahan Bakar & Rp. $3.000 .000,-$ \\
4 & Perbekalan & Rp. $4.500 .000,-$ \\
5 & Swadaya & Rp. & $100.000,-$ \\
\hline & TOTAL & Rp. &
\end{tabular}

$\mathrm{ML}_{1} \quad=$ Net Benefit - Komponen Biaya

$=5.335 .505 .000-1.796 .325 .000$

$=$ Rp. 3.539.180.000,-

\section{b. Pariwisata}

Harga tiket masuk kawasan wisata Waduk Malahayu adalah Rp. 4.000 dengan jumlah pengunjung ratarata dalam 5 tahun adalah 126.064 orang. Jadi penerimaan dari tiket rata-rata adalah Rp. 504.256 .000 per tahun.Untuk menilai ekonomi manfaat Waduk Malahayu sebagai obyek wisata yaitu dengan pendekatan biaya perjalanan (Travel Cost Method).Kesediaan membayar dan berkorban dalam pendekatan biaya perjalanan yang dilakukan oleh 30 responden akan tersaji dalam tabel berikut:

Tabel 5. Rata-Rata Per Orang Biaya Wisata Non Tiket Responden Waduk Malahayu dari Masing-Masing Daerah

\begin{tabular}{|c|c|c|c|c|c|c|}
\hline \multirow{2}{*}{ No } & \multirow{2}{*}{ Asal daerah } & \multirow{2}{*}{$\begin{array}{c}\text { Proporsi } \\
\text { asal } \\
\text { wisatawan } \\
(\%)\end{array}$} & \multicolumn{4}{|c|}{ Biaya (Rp) } \\
\hline & & & Transportasi & Konsumsi & Souvenir & Total \\
\hline 1 & Tanjung & 10 & Rp. 12.500 & Rp. 21.200 & Rp. 20.000 & Rp. 53.700 \\
\hline 2 & Pejagan & 3,3 & Rp. 15.000 & Rp. 20.000 & - & Rp. 35.000 \\
\hline 3 & Kersana & 3,3 & Rp. 10.000 & Rp. 25.000 & Rp. 5.000 & Rp. 40.000 \\
\hline 4 & Semarang & 6,7 & Rp. 50.000 & Rp. 47.500 & Rp. 35.000 & Rp. 132.500 \\
\hline 5 & Cirebon & 10 & Rp. 26.700 & Rp. 20.000 & Rp. 15.000 & Rp. 61.700 \\
\hline 6 & Larangan & 13,4 & Rp. 9.400 & Rp. 12.500 & Rp. 10.000 & Rp. 31.900 \\
\hline 7 & Ketanggungan & 10 & Rp. 10.000 & Rp. 22.700 & Rp. 10.000 & Rp. 42.700 \\
\hline 8 & Banjarharjo & 10 & Rp. 9.200 & Rp. 21.700 & Rp. 10.000 & Rp. 40.900 \\
\hline 9 & Kuningan & 3,3 & Rp. 30.000 & Rp. 30.000 & - & Rp. 60.000 \\
\hline 10 & Cilacap & 6,7 & Rp. 40.000 & Rp. 37.500 & - & Rp. 77.500 \\
\hline 11 & Brebes kota & 10 & Rp. 18.300 & Rp. 16.700 & Rp. 10.000 & Rp. 45.000 \\
\hline 12 & Tegal & 3,3 & Rp. 20.000 & Rp. 20.000 & - & Rp. 40.000 \\
\hline 13 & Cipajang & 3,3 & Rp. 15.000 & Rp. 20.000 & - & Rp. 35.000 \\
\hline \multirow[t]{2}{*}{14} & Sitanggal & 6,7 & Rp. 10.000 & Rp. 17.500 & - & Rp. 27.500 \\
\hline & TOTAL & 100 & & & & Rp. 723.400 \\
\hline
\end{tabular}


Jumlah biaya rata-rata yang dikeluarkan oleh 30 responden yaitu Rp. 723.400 sedangkan jumlah pengunjung pada tahun 2015 yaitu 126.064. Biaya rata-rata yang dikeluarkan tiap pengunjung yaitu Rp. 24.113,4 atau dibulatkan menjadi Rp. 24.100. Jika jumlah pengunjung tahun 2015 adalah 126.064, maka jumlah biaya yang dikeluarkan oleh pengunjung yaitu Rp. 3.038.142.400. Jadi nilai ekonomi Waduk Malahayu sebagai obyek wisata yaitu:

$\mathrm{ML}_{2}=$ Total Biaya Wisatawan + Biaya Tiket

$=$ Rp. 3.038.142.400+ Rp. 504.256.000

$=$ Rp. 3.542.398.400/tahun.

c.

Air Bersih

Air bersih yang berasal dari Waduk Malahayu digunakan oleh warga Desa Malahayu yang terdiri dari 15323 jiwa atau 3506 kepala keluarga yang tersebar dalam 13 dusun dan 33 RT. Penggunaan air bersih dari Waduk Malahayu dikenakan tarif Rp. 5000/bulan untuk tiap kepala keluarga. Jadi, total nilai manfaat langsung air bersih $\left(\mathrm{ML}_{3}\right)$ Waduk Malahayu yaitu sebesar Rp. 210.360.000,-.

d.

Transportasi Waduk

Biaya untuk penggunaan transportasi petani yaitu Rp. 5000,- untuk pulang pergi, sedangkan untuk wisatawan yaitu Rp. 10.000,-. Total penerimaan dari jasa transportasi waduk Malahayu tersaji dalam Tabel Berikut:

Tabel 6. Nilai penerimaan Jasa Transportasi Waduk Malahayu

\begin{tabular}{cccccc}
\hline \multirow{2}{*}{ Pengguna } & \multicolumn{2}{c}{ Jumlah Rata-Rata } & \multicolumn{2}{c}{ Penerimaan Rata-Rata } & \multicolumn{2}{c}{$\begin{array}{c}\text { Total } \\
\text { Penerimaan } \\
\end{array}$} & $\begin{array}{c}\text { Hari Biasa } \\
(\mathbf{R p})\end{array}$ & $\begin{array}{c}\text { Hari Libur } \\
(\mathbf{R p})\end{array}$ & $\begin{array}{c}\text { Hari Biasa } \\
(\mathbf{R p})\end{array}$ & $\begin{array}{c}\text { Hari Libur } \\
(\mathbf{R p})\end{array}$ & $\begin{array}{c}\text { (Rp) } \\
\text { Petani }\end{array}$ & 140 & 140 & 700.000 & 700.000 & 252.000 .000 \\
Wisatawan & 7 & 365 & 70.000 & 3.650 .000 & 236.420 .000 \\
\hline Jumlah & & & & & 488.420 .000 \\
\hline
\end{tabular}

Sumber : Hasil Penelitian

Ket : Pengguna Jasa Petani untuk Pulang Pergi

Untuk biaya penyusutan ada beberapa komponen yang tersaji dalam tabel berikut:

Tabel 7. Komponen Biaya Jasa Transportasi Waduk Malahayu

\begin{tabular}{cllr}
\hline No & \multicolumn{1}{c}{ Jenis } & & \multicolumn{2}{c}{ Nilai $($ Rp/Thn) } \\
\hline 1 & Depresiasi Aset & & \\
& - Perahu & Rp. & $1.500 .000,-$ \\
& - Mesin & Rp. & $1.017 .857,-$ \\
2 & Perawatan & Rp. & $742.857,-$ \\
3 & Bahan Bakar & Rp. & $7.309 .000,-$ \\
4 & Perbekalan & Rp. & $5.400 .000,-$ \\
5 & Retribusi & Rp. & $175.000,-$ \\
\hline & TOTAL & Rp. & $\mathbf{1 6 . 1 4 4 . 7 1 4 , -}$ \\
\hline
\end{tabular}

Nilai penyusutan komponen biayayaitu sebesar Rp. 16.144.714,- per orang dalam satu tahun, jika penyedia jasa transportasi ada 7 orang atau 7 perahu, maka nilai penyusutan komponen biayanya menjadi Rp. 113.012.998,-. Untuk mengetahui nilai ekonomi total jasa transportasi, maka dimasukkan dalam rumus:

$\mathrm{ML}_{4}=$ Penerimaan - Komponen Biaya

$=$ Rp. 488.420.000 - Rp. 113.012.998

$=$ Rp. 375.407.002/tahun 


\begin{tabular}{|c|c|c|}
\hline & Manfaat Langsung & $\begin{array}{l}\text { Nilai Ekonomi } \\
\text { (Rp/Thn) }\end{array}$ \\
\hline 1 & Perikanan Tangkap & Rp. 1.369 .180 .000 \\
\hline 2 & Pariwisata & Rp. 3.542 .398 .400 \\
\hline 3 & Air Bersih & $\begin{array}{ll}\text { Rp. } & 210.360 .000\end{array}$ \\
\hline \multirow[t]{2}{*}{4} & Transportasi & Rp. $\quad 375.407 .002$ \\
\hline & TOTAL & Rp. 5.497.345.402 \\
\hline
\end{tabular}

Total Ekonomi Manfaat Langsung

Tabel 8. Nilai Total Ekonomi Manfaat Langsung

\section{Manfaat Tidak Langsung}

Manfaat tidak langsung Waduk Malahayu yaitu sebagai daerah irigasi yang mengaliri 50 hektar area persawahan di kawasan Desa Malahayu. Biaya pengadaan air irigasi sawah rata-rata dari 10 responden yaitu Rp. $2.203 / \mathrm{m}^{2}$. Jadi nilai ekonomi waduk sebagai irigasi yaitu:

$$
\begin{aligned}
\text { Nilai ekonomi } & =\text { Luasan }\left(\mathrm{m}^{2}\right) \times \text { biaya } \\
& =500.000 \times \text { Rp. } 2.203 \\
& =\text { Rp. 1.101.500.000/tahun }
\end{aligned}
$$

\section{PEMBAHASAN}

\section{Manfaat Langsung}

\section{a. Perikanan Tangkap}

Ikan-ikan yang ada di Waduk Malahayu merupakan ikan hasil restocking yang diadakan oleh Kementrian Kelautan dan Perikanan bekerjasama dengan Dinas Kelautan dan Perikanan serta nelayan di Waduk Malahayu yang dilakukan tiap tahun berkisar antara bulan Februari-Maret. Waktu diperbolehkan untuk nelayan di waduk melakukan penangkapan ikan yaitu 2 bulan setelahrestocking, jadi waktu aktif untuk penangkapan ikan yaitu 10 bulan tiap tahun.

Nilai manfaat langsung Waduk Malahayu yaitu Rp. 5.335.505.000 per tahun yang merupakan nilai penerimaan/benefit, sedangkan nilai penyusutan komponen perikanan tangkap yaitu sebesar Rp. 1.796.325.000. Nilai ekonomi tersebut didapat dari pendekatan harga pasar dimana jumlah tangkapan per tahun dikalikan dengan harga ikan di pasaran. Dari nilai penerimaan dan nilai penyusutan per tahun maka akan diketahui nilai ekonomi total perikanan tangkap yaitu sebesar Rp. 3.539.180.000. Menurut Halomoan (2012), pendekatan harga pasar digunakan untuk mengetahui harga neto atau unit rent dari macam penggunaan sumber daya alam tersebut. Harga neto atau unit rent diperoleh dari harga pasar dikurangi total biaya produksi per unit (biaya-biaya yang dikeluarkan untuk mendapatkan komoditi tersebut per unitnya).Menurut Sofian (2003), pendekatan nilai pasar digunakan untuk komoditas-komoditas yang langsung dapat diperdagangkan dari ekosistem yang diteliti misalkan ikan, tambak dan sebagainya. Pendekatan ini digunakan untuk mendapatkan nilai uang bagi manfaat langsung dari ekosistem

\section{b. Pariwisata}

Pada 5 tahun terakhir, jumlah pengunjung selalu mengalami kenaikan dan dirata-rata pengunjung mencapai 126.064 orang per tahun. Harga tiket masuk kawasan wisata pada hari biasa dan pada hari libur sama yaitu Rp. 4000 untuk satu orang.Rata-rata biaya perjalanan responden secara keseluruhan dikelompokkan menurut asal daerah masing-masing.Ada 14 daerah asal dari 30 responden yaitu Tanjung, Pejagan, Kersana, Semarang, Cirebon, Larangan, Ketanggungan, Banjarharharjo, Kuningan, Cilacap, Brebes Kota, Tegal, Cipajang Dan Sitanggal. Biaya transportasi pulang pergi rata-rata responden tiap daerah asal yaitu berkisar antara Rp. 9.200 sampai Rp. 50.000, biaya konsumsi rata-rata responden tiap daerah asal berkisar dari Rp. 12.000 sampai Rp. 47.000 sedangkan biaya souvenir tidak semua responden membeli souvenir tetapi ada beberapa responden yang membeli dengan kisaran rata-rata Rp. 5.000 sampai Rp. 35.000.

Jumlah biaya perjalanan dari 30 responden yaitu Rp. 723.400 kemudian dirata-rata didapatkan hasil biaya perjalanan tiap individu yaitu Rp. 24.100. Jika jumlah pengunjung Waduk Malahayu ada 126.064, maka didapatkan hasil kesediaan membayar pengunjung sebesar Rp. 3.038.142.000 per tahun. Jadi nilai ekonomi Waduk Malahayu sebagai obyek wisata yaitu sebesar Rp. 3.542.398.400 per tahun.Manurut Sukirno (2004), penilaian (valuation) sumberdaya alam adalah alat ekonomi yang digunakan untuk mengestimasi nilai uang dari barang dan jasa yang diberikan oleh sumberdaya alam melalui teknik penilaian tertentu. Barang dan jasa yang dihasilkan dari sumberdayaalam dan lingkungan seperti nilai rekreasi, nilai keindahan, dan sebagainya yang tidak dapat diperdagangkan dan sulit mendapatkan data mengenai harga dan kuantitas dari barang dan jasa tersebut.Menurut Premono dan Kunarso (2010), pengembangan kegiatan pariwisata alam mempunyai dampak positif dan negatif, baik dari segi ekonomi, sosial, lingkungan dan masyarakat sekitar. Dampak positif dalam

\footnotetext{
${ }^{\circledR}$ Copyright by Management of Aquatic Resources (MAQUARES)
} 
pengembangan dapat berupa peningkatan pendapatan masyarakat, menambah pendapatan dan devisa negara, membuka kesempatan kerja dan usaha bagi masyarakat sekitar serta meningkatkan kesadaran masyarakat akan arti penting konservasi sumberdaya alam. Dampak negatif yang sering muncul dalam pe-ngembangan kegiatan kepariwisataan ini berupa tindakan pengrusakan (vandalisme) terhadap obyek wisata tersebut, baik bangunan maupun obyek alamnya.

\section{c. Air Bersih}

Pemanfaatan air bersih dari Waduk Malahayu dikenakan tarif Rp. 5.000 untuk penggunaan air selama satu bulan tiap satu kepala keluarga. Jumlah kepala keluarga di Desa Malahayu yang memanfaatkan air bersih dari waduk yaitu sebanyak 3506. Dengan tarif Rp. 5.000 dan jumlah kepala keluarga sebanyak 3506 maka akan didapat nilai manfaat langsung air bersih dari Waduk Malahayu sebesar Rp. 210.360.000 tiap tahun. Dari 58 responden, 96,55\% menyatakan bahwa mereka hanya mengandalkan air bersih dari Waduk Malahayu dikarenakan tidak atau belum tersedianya sumber air bersih yang dapat mencukupi kebutuhan mereka.Menurut Mays dan Tung (1997) dalam Syahrani et al.,(2004), mengelompokkan pemakaian air (water use) menjadi dua yaitu penggunaan konsumsi (consumptive use) dan penggunaan bukan konsumsi (non consumptive use). Penggunaan konsumsi meliputi kebutuhan air untuk pemakai pemukiman kota, pertanian, industri dan pertambangan. Sedangkan air bukan konsumsi berupa penggunaan air secara langsung pada badan sungai untuk penggunaan lainnya seperti tenaga air, transportasi dan rekreasi. Penyediaan air (water supply) menurut Linsley et al., ( 1992) dalam Agung (2000), adalah penyediaan air yang mampu menyediakan air minum (potable water) dalam jumlah yang cukup untuk kebutuhan pemukiman.

\section{d. Transportasi waduk}

Waduk Malahayu dimanfaatkan oleh masyarakat sekitar sebagai jalur transportasi menuju ke sawah mereka yang berada di tengah-tengah waduk dan yang berada di pinggiran Waduk Malahayu. Selain itu, sarana transportasi tersebut juga digunakan oleh wisatawan untuk menikmati pemandangan waduk dan berkeliling waduk. Nilai ekonomi manfaat langsung waduk sebagaitransportasi dilihat dari jumlah pengguna baik petani dan wisatawan per tahunnya.

Dengan jumlah petani sebanyak 140 tiap harinya dan biaya transportasi sebanyak Rp. 5000, maka nilai yang didapat yaitu Rp. 700.000 tiap hari untuk 7 orang penyedia jasa. Sehingga dalam 1 tahun, penerimaan biaya transportasi dari petani yaitu sebanyak Rp. 252.000.000. Sedangkan penerimaan dari wisatawan yaitu jumlah pengunjung hari biasa rata-rata hanya 7 orang tetapi pada saat hari libur rata-rata harian yaitu sebanyak 365 . Jadi, penerimaan dalam satu tahun yaitu Rp. 236.420.000 dari pengguna jasa transportasi wisatawan. Total penerimaan kotor dari jasa transportasi petani dan wisatawan apabila dijumlah yaitu sebesar Rp. 488.420.000.

Jumlah nilai penyusutan setiap penyedia jasa yaitu Rp. 144.714 per orang dalam satu tahun, jika penyedia jasa transportasi ada 7 orang maka nilai penyusutan komponen costnya menjadi Rp. 113.012.998. Nilai ekonomi toatal benefit transportasi di Waduk Malahayu yaitu Rp. 375.407.002 / tahun.

\section{Manfaat Tidak Langsung}

Irigasi

Dari data yang diberikan oleh Unit Pengelolaa Teknis (UPT) Waduk Malahayu, daerah yang teraliri irigasi dari waduk sebanyak 50 ha atau $500.000 \mathrm{~m}^{2}$. Di Desa Malahayu terdapat kelompok warga atau petani yang mengurusi irigasi bersama. Pengambilan sampel menggunakan metode purposive sampling dengan mengambil 10 responden petani yang menggunakan irigasi dari waduk. Dari 10 responden, mereka mempunyai sawah dengan luasan berkisar dari $140 \mathrm{~m}^{2}$ sampai $500 \mathrm{~m}^{2}$. Biaya irigasi dari yang responden keluarka tiap tahun berkisar dari Rp. 250.000 sampai Rp. 1.000 .000 atau rata-rata yaitu Rp. 473.200 per tahun. Biaya irigasi dapat dihitung berdasarkan luasan sawah yang responden miliki, tiap $1 \mathrm{~m}^{2}$ rata-rata biayanya yaitu Rp. 2.203. Jika luasan keseluruhan sawah yang di aliri air dari Waduk Malahayu adalah 50 ha atau $500.000 \mathrm{~m}^{2}$, maka jumlah nilai yang didapatkan yaitu Rp. 1.101.500.000/tahun.

\section{KESIMPULAN}

1. Nilai manfaat langsung Waduk Malahayu terdiri dari beberapa sektor, yaitu sektor perikanan tangkap yaitu sebesar Rp. 1.369.180.000 per tahun, pariwisata sebesar Rp. 3.542.398.400, air bersih sebesar Rp. 210.360.000 dan transportasi waduk sebesar Rp. 375.407.002. Jadi, nilai total manfaat langsung Waduk Malahayu yaitu sebesar Rp. 5.497.345.402 per tahun.

2. Nilai manfaat tidak langsung Waduk Malahayu yaitu sektor irigasi yaitu sebesar Rp. 1.101.500.000/tahun. 


\section{DAFTAR PUSTAKA}

Agung, R. P. 2000. Perhitungan Kebutuhan Air Non Irigasi dan Pemanfaatan Sumberdaya Air di Suatu Wilayah Kabupaten/Kota, Kasus Singkat Sumberdaya Air dalam Otonomi Daerah II. Universitas Gadjah Mada : Yogyakarta. Vol. 14 No. 3. Hlm : 201-210

Halomoan, H. 2012. Valuasi Ekonomi Danau Sentani di Kabupaten Jayapura. Jurnal Ecotrophic. Universitas Cendrawasih: Papua. Vol. 7(2):135-144

Koeshendrajana, S. 2008. Riset Identifikasi, Karakterisasi dan Valuasi Sosial Ekonomi Sumberdaya Perairan Umum Daratan. Laporan Teknis Kegiatan Penelitian. Balai Besar Riset Sosial Ekonomi Kelautan dan Perikanan

Premono, B. T. dan Kunarso, A. 2010. Valuasi Ekonomi Taman Wisata Alam Punti Kayu Palembang. Jurnal Penelitian Hutan dan Konservasi Alam. Balai Penelitian Kehutanan Palembang: Sumatera Selatan. Vol. VII No. $1: 13-23$

Sofian, A. 2003. Valuasi Ekonomi Pemanfaatan Hutan Mangrove di Kawasan Blanakan Kabupaten Subang, Jawa Barat. Institut Pertanian Bogor: Bogor

Sukirno, S. 2004. Pengantar Teori Mikro-ekonomi. PT. Raja Grafindo Persada: Jakarta

Syahrani. Djoko, L. Dan Fatchan, N. 2004. Analisis peran serta masyarakat dalam pengelolaan air bersih. Universitas Gadjah Mada: Yogyakarta. Vol. XI No. 2, hal: 89-95 